\title{
REDD1 overexpression in oral squamous cell carcinoma may predict poor prognosis and correlates with high microvessel density
}

\author{
YUANYONG FENG ${ }^{1}$, KAI SONG ${ }^{1}$, WEI SHANG ${ }^{1}$, LIQIANG CHEN ${ }^{1}$, \\ CHENGQIN WANG $^{2}$, BAOXING PANG ${ }^{1}$ and NING WANG ${ }^{2}$
${ }^{1}$ Department of Oral and Maxillofacial Surgery, School of Stomatology and The Affiliated Hospital of Qingdao University, Qingdao, Shandong 266003; ${ }^{2}$ Department of Pathology, Basic Medical College of Qingdao University, Qingdao, Shandong 266071, P.R. China

Received May 9, 2019; Accepted October 11, 2019

DOI: $10.3892 / \mathrm{ol} .2019 .11070$

\begin{abstract}
The association between the hypoxia-inducible gene termed regulated in development and DNA damage responses 1 (REDD1) and microvessel density (MVD) in human oral cancer has rarely been reported. The present study aimed to explore REDD1 expression in oral squamous cell carcinoma (OSCC), its clinical prognostic significance and its correlation with angiogenesis. REDD1 expression in 23 pairs of fresh-frozen OSCC and matched peritumoral mucosal tissues was quantified by reverse transcription-quantitative polymerase chain reaction (RT-qPCR) and western blotting. Furthermore, 74 formalin-fixed paraffin-embedded OSCC tissues were collected to detect REDD1 expression and CD34-positive MVD by immunohistochemistry (IHC). The association between REDD1 expression and MVD, patients' clinicopathological characteristics and cancerassociated survival rate was also evaluated using the log-rank (Mantel-Cox) test. The results from RT-qPCR and western blotting demonstrated that REDD1 expression was significantly higher in OSCC tissues compared with peritumoral mucosal tissues $(\mathrm{P}<0.05)$. In addition, the results from IHC revealed that REDD1 expression was higher in OSCC tissues compared with peritumoral tissues. Furthermore, REDD1 expression was associated with advanced clinical
\end{abstract}

Correspondence to: Dr Yuanyong Feng, Department of Oral and Maxillofacial Surgery, School of Stomatology and The Affiliated Hospital of Qingdao University, 16 Jiangsu Road, Qingdao, Shandong 266003, P.R. China

E-mail: feng_yuanyong@163.com

Dr Ning Wang, Department of Pathology, Basic Medical College of Qingdao University, 307 Ningxia Road, Qingdao, Shandong 266071, P.R. China

E-mail: ningwang7903@gmail.com

Key words: oral squamous cell carcinoma, hypoxia, regulated in development and DNA damage responses 1, angiogenesis, prognosis stage, poorer tumor differentiation, lymphatic metastasis and tumor recurrence $(\mathrm{P}=0.000, \mathrm{P}=0.003, \mathrm{P}=0.006$ and $\mathrm{P}<0.001$, respectively). Additionally, REDD1 overexpression was positively correlated with MVD ( $\mathrm{r}=0.7316 ; \mathrm{P}<0.001)$. The results from Kaplan-Meier survival analysis demonstrated a significantly reduced disease-free survival and overall survival in patients with OSCC and high REDD1 expression $(\mathrm{P}<0.001)$. REDD1 may therefore serve as a novel prognostic biomarker, a key regulatory checkpoint that could coordinate angiogenesis and a new therapeutic target for patients with OSCC.

\section{Introduction}

Tumor development is frequently associated with its microenvironment and activation of abnormal signaling pathways in the tumor, such as Hedgehog, Wnt, Notch, transforming growth factor- $\beta$ and AKT (1). For example, poor oxygenation or hypoxia is commonly found in solid tumors and affects tumor angiogenesis, heterogeneity, tumor progression and sensitivity to radiotherapy or chemotherapy $(1,2)$. This phenomenon is frequent in head and neck squamous cell carcinomas, in particular in oral squamous cell carcinomas (OSCCs) $(3,4)$, including that of the mouth floor, buccal mucosa, alveolar ridge, posterior molar triangle and hard palate, where the degree of tumor hypoxia has a crucial influence on chemoradiotherapy resistance, prognosis and patients' overall survival (OS) (5-8). Although early diagnosis and treatment methods have been developed in the past few years, local recurrence and lymph node metastasis remain the major factors influencing the prognosis of patients with OSCC (9), and the 5-year survival rate has not significantly improved over the past several decades (60\%) (10). Furthermore, advanced clinical manifestations, subtle symptomatology and rapid disease progression also contribute to OSCC poor prognosis $(11,12)$. It is therefore crucial to identify novel biomarkers that could provide a deeper understanding of the molecular mechanisms involved in oral carcinogenesis and OSCC progression, in order to identify better diagnostic methods and more effective prognostic indicators. 
Under hypoxic conditions, cancer cells exhibit reduced oxidative metabolism and initiate the protection of ATP by limiting certain energy-consuming processes, including protein synthesis of hypoxia-inducible factor (HIF) and mTOR (13). The effect of hypoxia on protein synthesis is partly mediated by the inhibition of mammalian target of rapamycin complex 1 (mTORC1) kinase (14), which is a central regulator of cell proliferation and protein translation $(15,16)$. The hypoxia-inducible gene named regulated in development and DNA damage response 1 (REDD1, also known as DDIT4/RTP801/Dig1), which was first discovered in 2002, is induced by hypoxia and other cellular stress as an upstream inhibitor of mTORC1 signaling and as an essential regulatory factor contributing to multiple DNA damage, which are widely expressed in many human tissues $(17,18)$. REDD1, which encodes a serine-rice 232 -amino acid cytoplasmic protein with an unknown functional domain, is localized to the human chromosome 10q24.33 and has one open reading frame and acid-coded prediction (18). REDD1-mediated mTOR inhibition occurs in cells exposed to hypoxia and cells responding to energy stress, and depends on the presence of the functional tuberous sclerosis (TSC)1/TSC2 inhibitory complex $(19,20)$.

To the best of our knowledge, the role of REDD1 in human oral cancer remains unclear. The present study aimed therefore to determine REDD1 expression in OSCC tissues, to evaluate whether REDD1 expression could be considered as a novel therapeutic target and a key regulatory checkpoint in OSCC and to explore its association with patients' clinicopathological characteristics and survival rate. In addition, since hypoxia is common in OSCC (7), the present study evaluated the association between REDD1 expression and microvessel density (MVD) in order to further understand the underlying mechanism of REDD1 in OSCC.

\section{Materials and methods}

Patients and tissue specimens. A total of 23 pairs of fresh-frozen (stored in liquid nitrogen) OSCC tissues and matched peritumoral mucosal tissues (distance from tumor edge, $>2 \mathrm{~cm}$ ) obtained from 23 patients with OSCC between January 2017 and December 2018, and 93 formalin-fixed paraffin-embedded tissue samples (74 primary OSCC and 19 peritumoral mucosa) obtained from 74 patients with OSCC between January 2007 and December 2012, were collected from the Affiliated Hospital of Qingdao University. Histopathological evaluation was performed independently by two pathologists. All diagnoses were made according to the pathology criteria of head and neck tumors of the 4th edition of the World Health Organization classification of tumors in 2017 (21). Clinical, demographic and pathological data from all patients are listed in Tables I and II. The study was approved and supervised by the Institutional Medical Ethics Committee of the Affiliated Hospital of Qingdao University, and written informed consent was obtained from each patient. Tumors were staged and graded according to clinical TNM stage and histologic grade of the National Comprehensive Cancer Network (NCCN) guidelines (22). There were 34 stage I/II tumors and 40 stage III/IV tumors. The 74 patients were followed up by interview at the clinic or by telephone for 5 years. The last follow-up time-point was in December 2017, where 26 patients had died and 48 patients were alive. Among the 74 patients, 18 had tumor recurrence. The median age of the patients was 57.8 years (age range, $36-79$ years).

Total RNA isolation and reverse transcription-quantitative polymerase chain reaction ( $R T-q P C R)$. RNA isolation and RT-qPCR were performed as described previously $(23,24)$. Total RNA was extracted from 23 fresh-frozen OSCC and matched peritumoral mucosal tissues using an RNAprep pure tissue kit (Tiangen Biotech Co., Ltd.) according to the manufacturer's instructions. Each sample was performed in triplicate. The concentration and integrity of RNA preparations were assessed with an EON analyzer (BioTek Instruments, Inc.) using Gene5 software (version 5; BioTek Instruments, Inc.). The sequences of the primers used were as follows: REDD1 forward, 5'-GAGCCTGGAGAGCTCGGACT-3' and reverse, 5'-CTGCATCAGGTTGGCACACA- 3 ; ; and $\beta$-actin forward, 5'-CCCTGGAGAAGAGCTACGAG-3' and reverse, 5'-GGA AGGAAGGCTGGAAGAGT-3' (Genomics). RT-qPCR amplification reactions were performed using a PCR Real-Time system (Bio-Rad CFX96; Bio-Rad Laboratories, Inc.) as follows: Denaturation at $95^{\circ} \mathrm{C}$ for $15 \mathrm{~min}$, followed by 39 cycles of $95^{\circ} \mathrm{C}$ for $10 \mathrm{sec}, 53^{\circ} \mathrm{C}$ for $30 \mathrm{sec}$ and $72^{\circ} \mathrm{C}$ for $30 \mathrm{sec}$, with a final extension at $72^{\circ} \mathrm{C}$ for $10 \mathrm{~min}$. The relative expression levels of REDD1 were normalized to the endogenous control $\beta$-actin and were expressed as $2^{-\Delta \Delta \mathrm{Cq}}(25)$. Each run included a standard curve and a buffer blank control without template to test for contamination of analytical reagent. PCR products were also visualized using an AlpaImagerHP System (ProteinSimple) following electrophoresis on $1 \%$ agarose gels with ethidium bromide dye.

Western blotting. Tissue proteins from 23 fresh-frozen OSCC and matched peritumoral mucosal tissues were extracted as previously described (26). The tissue of each sample $(20 \mathrm{mg})$ was rapidly lysed in an ice-cold RIPA lysis containing protease and phosphatase inhibitor (Beyotime Institute of Biotechnology) for $30 \mathrm{~min}$. The lysates were centrifuged at $12,000 \mathrm{x} \mathrm{g}$ for $25 \mathrm{~min}$ at $4^{\circ} \mathrm{C}$. The protein concentration was measured using the Micro BCA Protein Assay kit (Beyotime Institute of Biotechnology). Protein was denatured by boiling for $10 \mathrm{~min}$ before electrophoresis. The protein sample $(20 \mu \mathrm{g})$ was separated by $10 \%$ SDS-PAGE and transferred onto nitrocellulose membranes. Membranes were blocked with TBS containing $0.1 \%$ Tween-20 and 5\% skimmed milk powder on a shaker for $2 \mathrm{~h}$ at room temperature, and incubated overnight at $4^{\circ} \mathrm{C}$ with the following primary antibodies: Polyclonal rabbit anti-REDD1 (1:1,000; cat. no. 10638-1-AP; ProteinTech Group, Inc.) and monoclonal mouse anti- $\beta$-actin (1:5,000; cat. no. 66009-1; ProteinTech Group, Inc.). Membranes were then incubated with horseradish peroxidase-conjugated secondary antibody (1:5,000; cat. no. SA00001-1; ProteinTech Group, Inc.). Clarity ${ }^{\mathrm{TM}}$ Western enhanced chemiluminescence substrate and imaging system (Bio-Rad Laboratories, Inc.) were used to detect the signal on the membrane. The data were analyzed via densitometry using ImageJ software V1.6.0 (National Institutes of Health) and normalized to expression of the internal control $\beta$-actin. Each experiment was repeated three times and the data represent the means of the three experiments. 
Table I. Clinicopathological characteristics of the 23 patients with oral squamous cell carcinoma.

\begin{tabular}{lr}
\hline Clinicopathological characteristics & $\mathrm{n}(\%)$ \\
\hline Age, years & \\
$\leq 57.8$ & $11(47.83)$ \\
$>57.8$ & $12(52.17)$ \\
Sex & \\
Male & $16(69.57)$ \\
Female & $7(30.43)$ \\
Tumor size, cm & \\
$\leq 4$ & $13(56.52)$ \\
$>4$ & $10(43.48)$ \\
TNM stage & \\
I, II & $10(43.48)$ \\
III, IV & $13(56.52)$ \\
Histological grade & \\
G1 & $12(52.17)$ \\
G2 & $9(39.13)$ \\
G3 & $2(8.70)$ \\
Lymphatic metastasis & \\
Negative & $9(39.13)$ \\
Positive & $14(60.87)$ \\
\hline
\end{tabular}

Tissue microarray construction and immunohistochemistry $(I H C)$. After interpreting the known pathological results of each paraffin-embedded tissue block, tissue microarrays (TMAs) were constructed by selecting one representative block from each case specimen and taking two core tissue regions from morphologically representative areas of the block (26). Several different TMA blocks were constructed with 1-mm-diameter cylinders in new wax $(97.5 \%$ paraffin and $2.5 \%$ beeswax mixed at $55^{\circ} \mathrm{C}$ for $10 \mathrm{~min}$ ), each containing 42 cylinders. The blocks then were sectioned at a thickness of $4 \mu \mathrm{m}$ and placed on slides coated with 3-aminopropyltriethoxysilane for immunohistochemistry (IHC).

IHC was performed on TMA sections as previously described (24). The primary antibodies used for IHC were as follows: Monoclonal rabbit anti-CD34 (1:200; cat. no. ab81289; Abcam) and polyclonal rabbit anti-REDD1 (1:100; cat. no. 10638-1-AP; ProteinTech Group, Inc.). Following deparaffination and rehydration, slides were heated for $5 \mathrm{~min}$ at $95^{\circ} \mathrm{C}$ for antigen retrieval in a microwave oven in EDTA buffer. The sections were then washed with phosphate buffer saline (PBS), and the endogenous peroxidase activity was blocked with $3 \% \mathrm{H}_{2} \mathrm{O}_{2}$ for $10 \mathrm{~min}$ at room temperature. Following PBS washes, slides were blocked with $0.5 \%$ BSA at room temperature for $20 \mathrm{~min}$, respective primary antibodies were incubated with anti-REDD1 or anti-CD34 antibodies overnight at $4^{\circ} \mathrm{C}$ in a humidity chamber, followed by the addition of the secondary antibody (1:1,000; cat. no. SA00001-1; ProteinTech Group, Inc.) at $37^{\circ} \mathrm{C}$ for $30 \mathrm{~min}$. Following PBS washes for $3 \mathrm{~min}$, the reaction product was visualized using 3'-diaminobenzidine substrate kit (Dako; Agilent Technologies, Inc.) for $5 \mathrm{~min}$ at room temperature. Subsequently, the sections were counterstained with hematoxylin for 2 min at room temperature. Negative control sections were incubated with PBS instead of primary antibody. The slides were covered, sealed and examined under a light microscope (Olympus Corporation). Five fields of view (magnification, x100) were randomly selected and photographed. IHC staining for REDD1 and CD34 was independently analyzed by two pathologists, without knowledge of the patients' clinical information. The IHC scoring criteria for REDD1 used in the present study was the same as previously described (26). The scaled scores were based on the estimated proportion of positive tumor cells and analyzed by Image Pro Plus 6.0 (Media Cybernetics, Inc.). The scores were classified as $0,1,2,3$ or 4 for $0,<10,10-33,33-66$ or $>66 \%$ of positively stained cells proportion, respectively. The score intensity indicated the average intensity of the positive tumor cells and was defined as negative, weak, intermediate or strong, for scores of $0,1,2$ or 3 , respectively. The proportion of positively stained cells and intensity scores were then added to obtain a total score ranging between 0 and 7 . All specimens were divided into three groups for further statistical analyses according to the following criteria: i) Negative/weak expression, 0-3 points; ii) moderate expression, 4-5 points; and iii) strong expression, 6-7 points.

MVD was calculated according to the positive staining of CD34 marker on vascular endothelial cells (VECs) according to the method described by Weidner et al (27). The number of highest density area of CD34-positive expressing cells was designated as hot spots at low magnification, and VEC cluster that was clearly distinguished from the surrounding tumor cells and connective tissue was counted as a microvessel in high power fields. The microvessel numbers in five high power fields of each hot spot and in five hot spots of each section were recorded as the MVD value. In the present study, the median MVD value of all specimens was used to distinguish between tissues with high and low levels of vascular expression.

Statistical analysis. All data were statistically analyzed using SPSS statistical software version 17.0 (SPSS, Inc.). The results are expressed as the mean \pm standard deviation. Unpaired Student's t-tests were used for comparisons of two groups of data. Multiple comparisons were evaluated by one-way ANOVA followed by Student-Newman-Keuls test. Pearson's $\chi^{2}$ test was used to examine the association between REDD1 expression and the patients' clinicopathological characteristics, and to examine the association between MVD and the patients' clinicopathological characteristics, and was also used to compare REDD1 expression between OSCC and peritumoral mucosal tissues. Spearman's correlation analysis and linear regression were used to examine the correlation between MVD counts and REDD1 expression. Survival analysis according to the different REDD1 expression groups was performed using the Kaplan-Meier method and compared by the log-rank (Mantel-Cox) test. $\mathrm{P}<0.05$ was considered to indicate a statistically significant difference.

\section{Results}

REDD1 mRNA expression in 23 fresh-frozen OSCC and matched peritumoral mucosal tissues. The mRNA expression level of REDD1 in OSCC tissues and matched peritumoral 
Table II. Association between REDD1, MVD expression and clinicopathological characteristics of 74 patients with OSCC.

\begin{tabular}{|c|c|c|c|c|c|c|c|}
\hline \multirow{2}{*}{$\begin{array}{l}\text { Clinicopathological } \\
\text { characteristics }\end{array}$} & \multirow[b]{2}{*}{ Cases $(\%)$} & \multicolumn{2}{|c|}{ REDD1 expression } & \multirow[b]{2}{*}{ P-value } & \multicolumn{2}{|c|}{ MVD } & \multirow[b]{2}{*}{ P-value } \\
\hline & & Negative/weak (0-3) & Moderate/strong (4-7) & & $\leq 35$ & $>35$ & \\
\hline \multicolumn{8}{|l|}{ Age, years } \\
\hline$\leq 57.8$ & $36(48.65)$ & 22 & 14 & 0.610 & 20 & 16 & 0.481 \\
\hline$>57.8$ & $38(51.35)$ & 21 & 17 & & 18 & 20 & \\
\hline \multicolumn{8}{|l|}{ Sex } \\
\hline Male & $50(67.57)$ & 29 & 21 & 0.978 & 27 & 23 & 0.511 \\
\hline Female & $24(32.43)$ & 14 & 10 & & 11 & 13 & \\
\hline \multicolumn{8}{|l|}{ Tumor size, $\mathrm{cm}$} \\
\hline$\leq 4$ & $42(56.76)$ & 25 & 17 & 0.777 & 22 & 20 & 0.839 \\
\hline$>4$ & $32(43.24)$ & 18 & 14 & & 16 & 16 & \\
\hline \multicolumn{8}{|l|}{ TNM stage } \\
\hline I, II & 34 (45.95) & 28 & 6 & $<0.001$ & 22 & 12 & 0.034 \\
\hline III, IV & $40(54.05)$ & 15 & 25 & & 16 & 24 & \\
\hline \multicolumn{8}{|l|}{ Histological grade } \\
\hline G1 & $39(52.70)$ & 29 & 10 & 0.003 & 25 & 14 & 0.011 \\
\hline G2 & $28(37.84)$ & 13 & 15 & & 12 & 17 & \\
\hline G3 & $7(9.46)$ & 1 & 6 & & 1 & 5 & \\
\hline \multicolumn{8}{|l|}{ Lymphatic metastasis } \\
\hline Negative & $40(54.05)$ & 29 & 11 & 0.006 & 27 & 13 & 0.003 \\
\hline Positive & $34(45.95)$ & 14 & 20 & & 11 & 23 & \\
\hline \multicolumn{8}{|l|}{ Tumor recurrence } \\
\hline Yes & $18(24.32)$ & 0 & 18 & $<0.001$ & 3 & 15 & 0.002 \\
\hline No & $56(75.68)$ & 43 & 13 & & 35 & 21 & \\
\hline OSCC tissues & 74 & $43(58.1 \%)$ & $31(41.9 \%)$ & $<0.001$ & 38 & 36 & \\
\hline Peritumoral mucosa & 19 & $19(100 \%)$ & $0(0 \%)$ & & & & \\
\hline
\end{tabular}

MVD, microvessel density; OSCC, oral squamous cell carcinoma; REDD1, regulated in development and DNA damage responses 1; TNM, Tumor-Node-Metastasis.

mucosa was detected by RT-qPCR. The results demonstrated that REDD1 mRNA level was significantly higher in the 23 OSCC tissues compared with matched peritumoral mucosa (Figs. 1A and E and S1; P<0.05). Furthermore, the mRNA expression level of REDD1 was associated with histopathological grade. In particular, the difference in REDD1 expression in highly, moderately and poorly differentiated (G1, G2 and G3) OSCCs was statistically significant (Fig. 1B and $\mathrm{F} ; \mathrm{P}<0.01)$. The melting curves for REDD1 expression are presented in Fig. 1C and D to show that it had no non-specific amplification.

Western blotting analysis of REDD1 expression in primary OSCC and matched mucosal tissues. The protein expression of REDD1 varied greatly among the 23 fresh-frozen OSCC tissues. Compared with matched peritumoral mucosa tissues, the protein expression of REDD1 was significantly increased in the 23 fresh-frozen OSCC tissues (Figs. 2A and 2C and S2; $\mathrm{P}<0.001)$. In addition, there were statistically significant differences of REDD1 expression in highly, moderately and poorly differentiated (G1, G2 and G3) OSCCs (Fig. 2B and D; P<0.01).
REDD1 and CD34 IHC in OSCC and peritumoral mucosal tissues. REDD1 and CD34 IHC staining was performed on 74 primary OSCC and 19 peritumoral mucosal specimens. The results demonstrated that REDD1 was mainly expressed in tumor cells from OSCC tissues, whereas CD34 was mainly expressed in VECs of blood vessels (Figs. 3A-D and 4A-F). The expression of REDD1 protein was different in tumors and peritumoral tissues, and exhibited heterogeneity in tumor tissues. The percentage of OSCC tissues with negative/weak and moderate/strong REDD1 expression was 58.1\% (43/74; Fig. 3B; Table II) and 41.9\% (31/74; Fig. 3C and D; Table II), respectively; however, REDD1 expression was weak or negative in all peritumoral mucosal tissues (0/19; Fig. 3A; $\mathrm{P}<0.001$; Table II). In addition, REDD1 expression was significantly increased in G2 and G3 OSCC tissues compared with G1 tissues in a grade-dependent manner $(\mathrm{P}<0.01$ and $\mathrm{P}<0.001$, respectively; Fig. $3 \mathrm{E}$ and $\mathrm{F})$. Furthermore, the median MVD count was 35 among all OSCC tissues, and the numbers of samples with low and high MVD were 38 (of 74; MVD $\leq 35$ ) and 36 (of 74; MVD >35), respectively. 

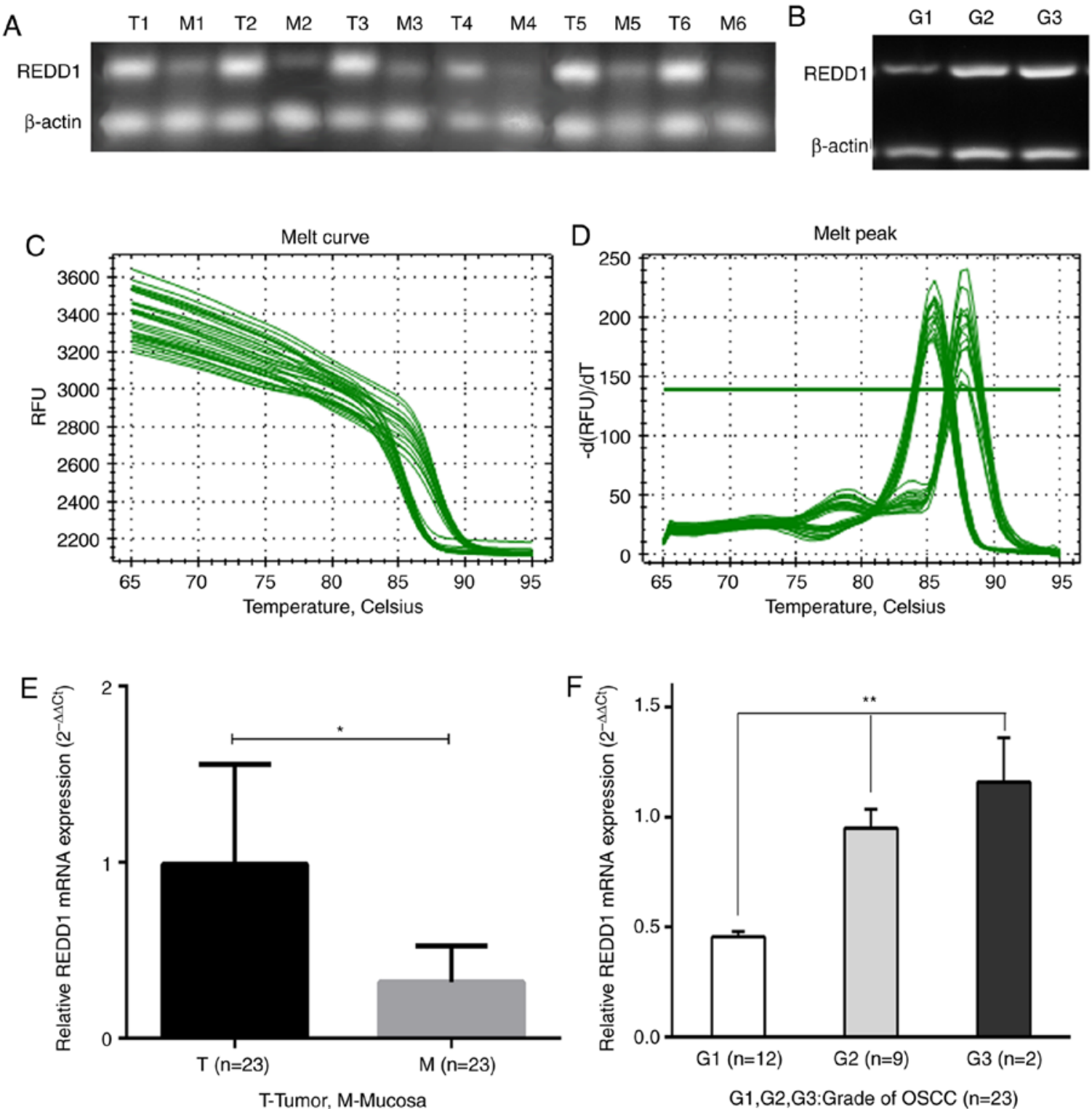

Figure 1. High mRNA expression of REDD1 in OSCC tissues. (A) Representative bands of REDD1 and $\beta$-actin in OSCC and matched peritumoral mucosa tissue following agarose gel electrophoresis and RT-qPCR. REDD1 expression level was higher in OSCC tissue (T1-T6) compared with matched peritumoral mucosa (M1-M6). (B) Representative bands of REDD1 mRNA relative to $\beta$-actin levels in OSCC tissues of different histological grades. REDD1 mRNA expression was higher in poorly-differentiated OSCC tissue (G3) compared with highly-differentiated OSCC (G1). (C) Melt curves for the expression of REDD1 and $\beta$-actin were assessed in OSCC tissue and matched peritumoral mucosa by RT-qPCR. (D) Melt peak showed a single peak indicating the specific amplification of mRNA. (E) Evaluation of Ct values for RT-qPCR expressed as $2^{-\Delta \Delta C q}$. The relative expression of REDD1 was significantly higher in 23 OSCC tissues compared with the matched peritumoral mucosa. ${ }^{*} \mathrm{P}<0.05$. (F) Relative expression $\left(2^{-\Delta \Delta C q}\right)$ of REDD1 was significantly higher in poorly-differentiated OSCC tissue (G3, G2) compared with highly-differentiated OSCC (G1) in 23 fresh-frozen OSCC tissues. ${ }^{* *} \mathrm{P}<0.01$. M, mucosa; OSCC, oral squamous cell carcinoma; REDD1, regulated in development and DNA damage responses 1; RFU, relative fluorescence unit; RT-qPCR, reverse transcription-quantitative polymerase chain reaction; $\mathrm{T}$, tumor.

Associations between REDDI expression or MVD and patients' clinicopathological characteristics. VECs staining for CD34 in areas of neovascularization was used to detect the MVD in OSCC specimens. The association between REDD1 expression or MVD count and patients' clinicopathological characteristics was analyzed in 74 OSCC tissues. The results demonstrated that both REDD1 expression and MVD counts were significantly associated with clinical TNM stage $(\mathrm{P}<0.001$ and $\mathrm{P}=0.034$, respectively), histological grade $(\mathrm{P}=0.003$ and $\mathrm{P}=0.011$, respectively), lymphatic metastasis $(\mathrm{P}=0.006$ and $\mathrm{P}=0.003$, respectively) and tumor recurrence $(\mathrm{P}<0.001$ and $\mathrm{P}=0.002$, respectively; Table II). However, REDD1 expression and MVD counts were not associated with age, sex and tumor size $(\mathrm{P}>0.05$; Table II).

Correlation between REDD1 expression and MVD in OSCC tissues. To investigate the correlation between REDD1 expression and MVD in OSCC tissues, Spearman's correlation analysis and linear regression were used. Among the 43 cases of OSCC with negative/weak REDD1 expression, 33 presented with low MVD and the other 10 cases exhibited high MVD (Table III, Fig. 4A and B). Conversely, in the 31 samples with moderate/strong expression, 26 had low MVD, whereas the other five cases presented with a low MVD count (Table III, 

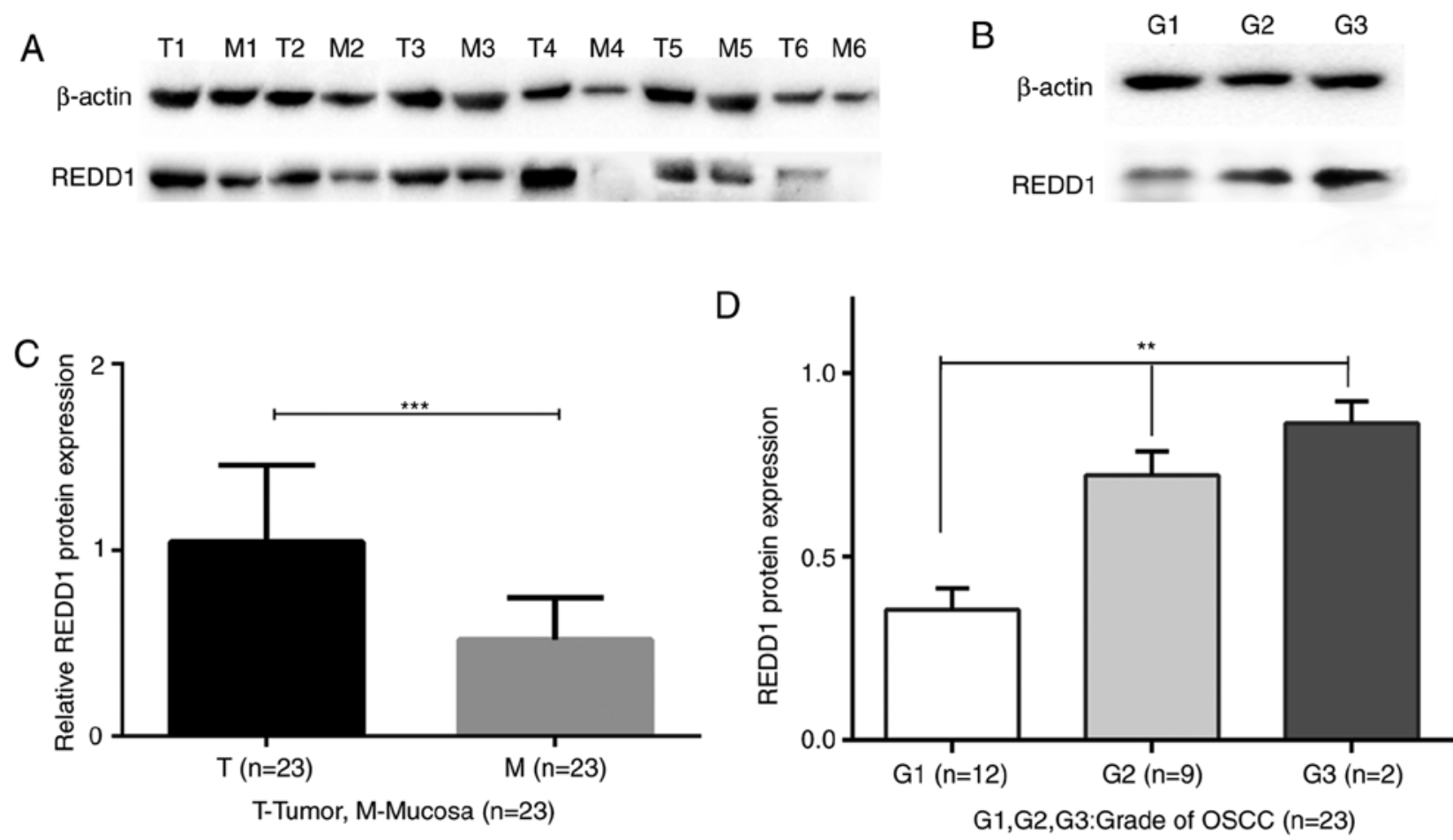

Figure 2. REDD1 is overexpressed in OSCC tissues. (A) REDD1 was highly expressed in OSCC tissues (T1-T6), but not in matched peritumoral mucosa (M1-M6). (B) Representative REDD1 expression was different in highly, moderately and poorly differentiated (G1, G2 and G3) OSCCs in 23 fresh-frozen OSCC tissues. (C) Relative REDD1 expression was significantly higher in the 23 OSCC tissues compared with the 23 matched peritumoral mucosa. (D) REDD1 expression was significantly higher in poorly-differentiated OSCC tissue (G3 and G2) compared with highly differentiated OSCC (G1) in 23 fresh-frozen OSCC tissues. ${ }^{* *} \mathrm{P}<0.01$ and ${ }^{* * * *} \mathrm{P}<0.001$. M, mucosa; OSCC, oral squamous cell carcinoma; REDD1, regulated in development and DNA damage responses 1; T, tumor.

Fig. 4C-F). The results demonstrated that REDD1 expression and MVD count were positively correlated in OSCC samples $(\mathrm{P}<0.0001 ; \mathrm{r}=0.7316$; Fig. 4G). Furthermore, moderate or strong REDD1 expression in tumors was significantly correlated with higher MVD, compared with weak or negative REDD1 expression in tumors $(\mathrm{P}<0.0001$; Table III). These results suggested that REDD1, as an upstream gene of MVD, may be considered as a key regulatory checkpoint that could coordinate vascular growth signaling inputs.

Kaplan-Meier analysis of disease-free survival (DFS) and OS in patients with OSCC according to REDDI expression. The results demonstrated that patients with negative/weak REDD1 expression presented significantly increased DFS and OS rates compared with patients with moderate/strong REDD1 expression ( $\mathrm{P}<0.0001$, respectively; Fig. 5A and B). REDD1 overexpression may therefore serve as a biomarker for prognosis of patients with OSCC.

\section{Discussion}

REDD1 protein is present at low level in most mature tissues (18). Previous studies reported that REDD1 could be a transforming oncogene in solid cancer types, such as pancreatic, ovarian and breast cancer (28-30). The results from the present study demonstrated that REDD1 expression was significantly higher in OSCC tissues compared with peritumoral mucosa. In addition, poorly differentiated OSCC was associated with higher REDD1 expression, whereas it was not the case for highly differentiated OSCC. Furthermore, patients with high REDD1 expression had a more advanced clinical stage, higher rate of lymphatic metastasis and recurrence, and shorter DFS and OS. These results suggested that REDD1 may function as an oncogene in OSCC, and that changes in REDD1 expression may serve a role in oral carcinogenesis and OSCC progression, which is consistent with findings from previous studies in prostate cancer (31), breast cancer (32) and ovarian carcinoma (33). In addition, the present study demonstrated that REDD1 expression in low grade OSCC (G1) was lower than that in high grades (G2 and G3) OSCC, which was consistent with previous studies reporting $(32,33)$ that REDD1 expression is reduced in certain slow-growing tumors, including certain low-grade ovarian cancers (34).

Hypoxia is known to be present during tumor growth, such as ovarian, colorectal, brain cancer and small cell lung cancer $(13,35)$, which is also the case in OSCC. Since hypoxia and increased oxidative stress can induce REDD1 overexpression (18), REDD1 gene was initially identified as a stress response gene. However, REDD1 was subsequently confirmed to also be induced in response to glucocorticoid treatment (36), nutrient deprivation (37) and other stress conditions $(19,38,39)$. Because one reason is that tumor growth occurs at a faster rate than angiogenesis, hypoxia and nutrient deficiencies are known to persist in the cancer microenvironment (35). Under continuous hypoxia, cancer cells exhibit reduced oxidative metabolism and self-limiting energy expenditure (13), which stimulates REDD1 protein synthesis. In the present study, the results from IHC demonstrated that high REDD1 expression was significantly associated with increased MVD. This may be due to the fact that angiogenesis occurs at a much slower 
A
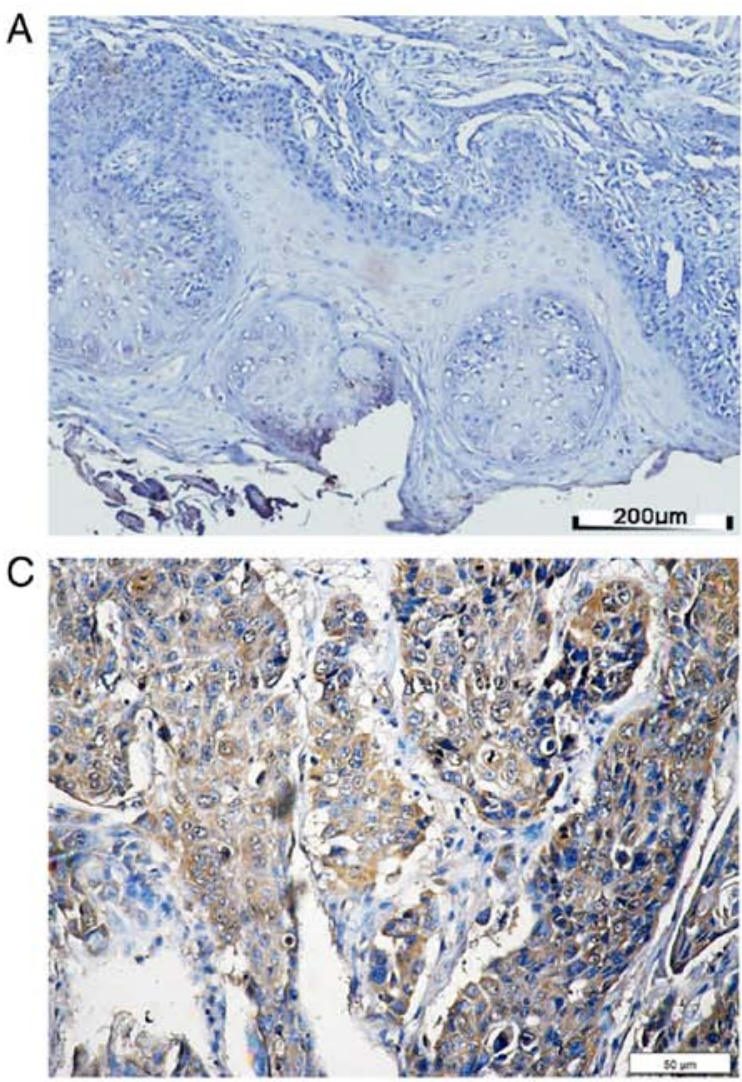

B
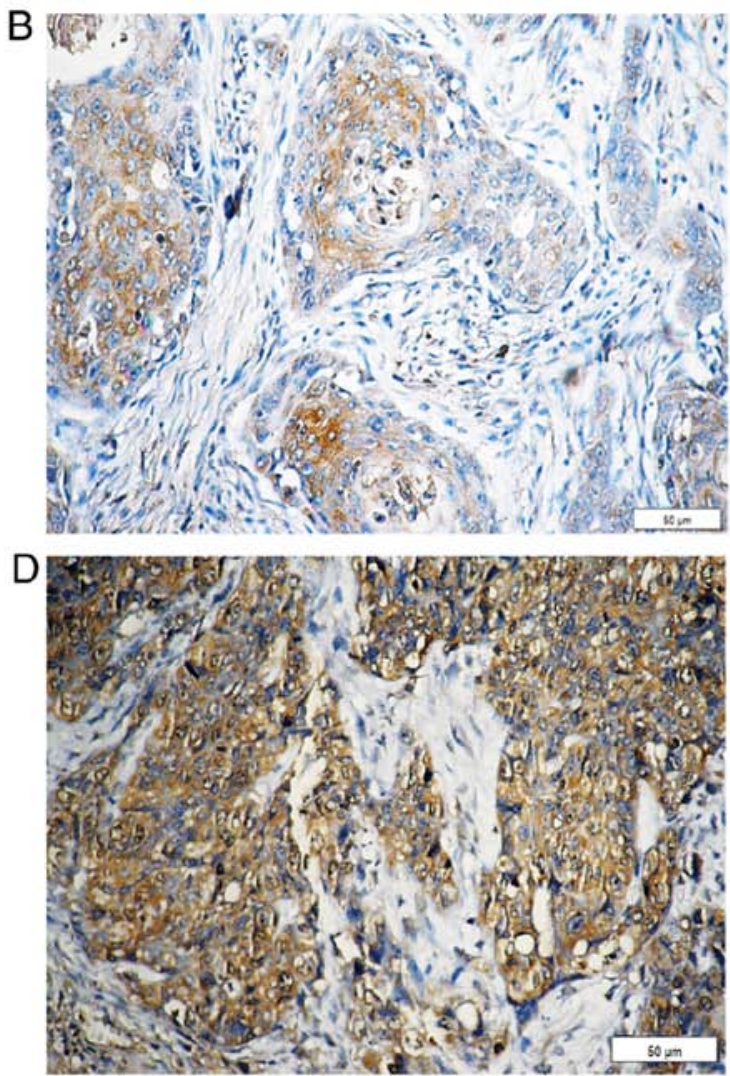

F

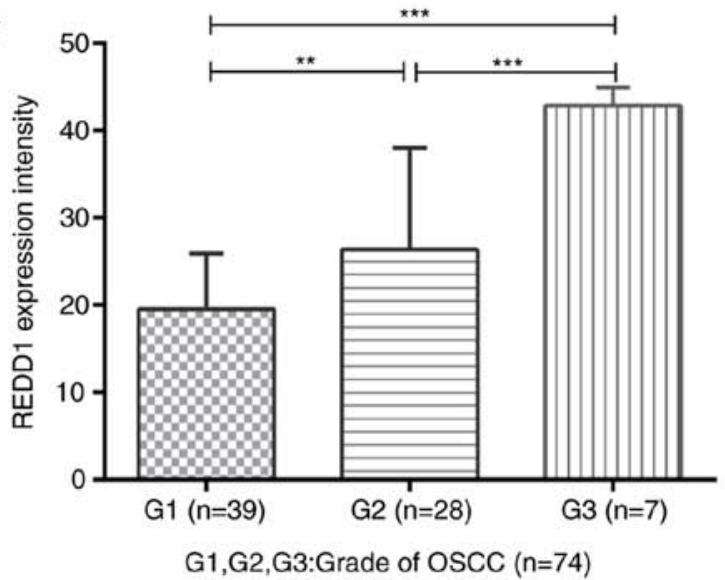

Figure 3. IHC staining for REDD1 in OSCC and peritumoral mucosal tissues. Paraffin-embedded sections of OSCC and adjacent tissues were stained using an anti-REDD1 polyclonal antibody. (A) Representative REDD1 IHC staining of negative/weak expression in peritumoral mucosal specimen. Scale bar, $200 \mu \mathrm{m}$. (B) Representative REDD1 IHC staining of weak expression in highly-differentiated OSCC tissue (G1). Scale bar, 50 $\mu \mathrm{m}$. (C) Representative REDD1 IHC staining of moderate expression in moderately-differentiated OSCC tissue (G2). Scale bar, $50 \mu \mathrm{m}$. (D) Representative REDD1 IHC staining of moderate/strong-expression in poorly differentiated OSCC tissue. Scale bar, $50 \mu \mathrm{m}$. (E) REDD1 expression intensity in 74 primary OSCC and 19 peritumoral mucosal specimens. (F) REDD1 expression intensity in differently-differentiated OSCC tissue $(\mathrm{G} 1, \mathrm{n}=39 ; \mathrm{G} 2, \mathrm{n}=28 ; \mathrm{G} 3, \mathrm{n}=7)$. ${ }^{* *} \mathrm{P}<0.01,{ }^{* * *} \mathrm{P}<0.001$. IHC, immunohistochemistry; OSCC, oral squamous cell carcinoma; REDD1, regulated in development and DNA damage responses 1.

rate than tumor growth, which inevitably diminishes the blood supply to the tumor, resulting in hypoxia and poor tumor nutrition, and increased REDD1 expression. Conversely, hypoxia also leads to angiogenesis in tumors (35). Despite active angiogenesis, tumor novel vessels are highly irregular and leaky and function poorly (35). Even in the case of vascular-rich tumors, these defective vascular properties induce tumor ischemia, resulting in continued hypoxia that leads to stable REDD1 expression (35), which is another reason that hypoxia leads to REDD1 overexpression. This phenomenon was also observed in the study, although MVD expression was higher in the moderately and poorly differentiated OSCC tissues and REDD1 expression was increased accordingly.

REDD1 is expressed in response to numerous stress conditions and is also an important regulator of the response to a number of transcription factors, including p53, p63, activating transcription factor 4, Sp1 and HIF-1 $(18,40,41)$. Previous studies reported that REDD1 expression is upregulated in numerous types of cancer, including ovarian cancer $(33,34)$, breast cancer (32), pancreatic ductal adenocarcinoma (42) and 
Table III. Correlation between REDD1 expression and MVD in 74 oral squamous cell carcinoma tissues.

\begin{tabular}{|c|c|c|c|c|c|}
\hline \multirow[b]{2}{*}{ REDD1 expression } & \multirow[b]{2}{*}{ Groups (\%) } & \multicolumn{2}{|c|}{ MVD } & \multirow[b]{2}{*}{$\mathrm{r}$} & \multirow[b]{2}{*}{ P-value } \\
\hline & & $\leq 35$ & $>35$ & & \\
\hline Negative/weak (0-3) & $43(58.11)$ & 33 & 10 & & \\
\hline Moderate/strong (4-7) & $31(41.89)$ & 5 & 26 & 0.7316 & $<0.0001$ \\
\hline
\end{tabular}

MVD, microvessel density; REDD1, regulated in development and DNA damage responses 1.
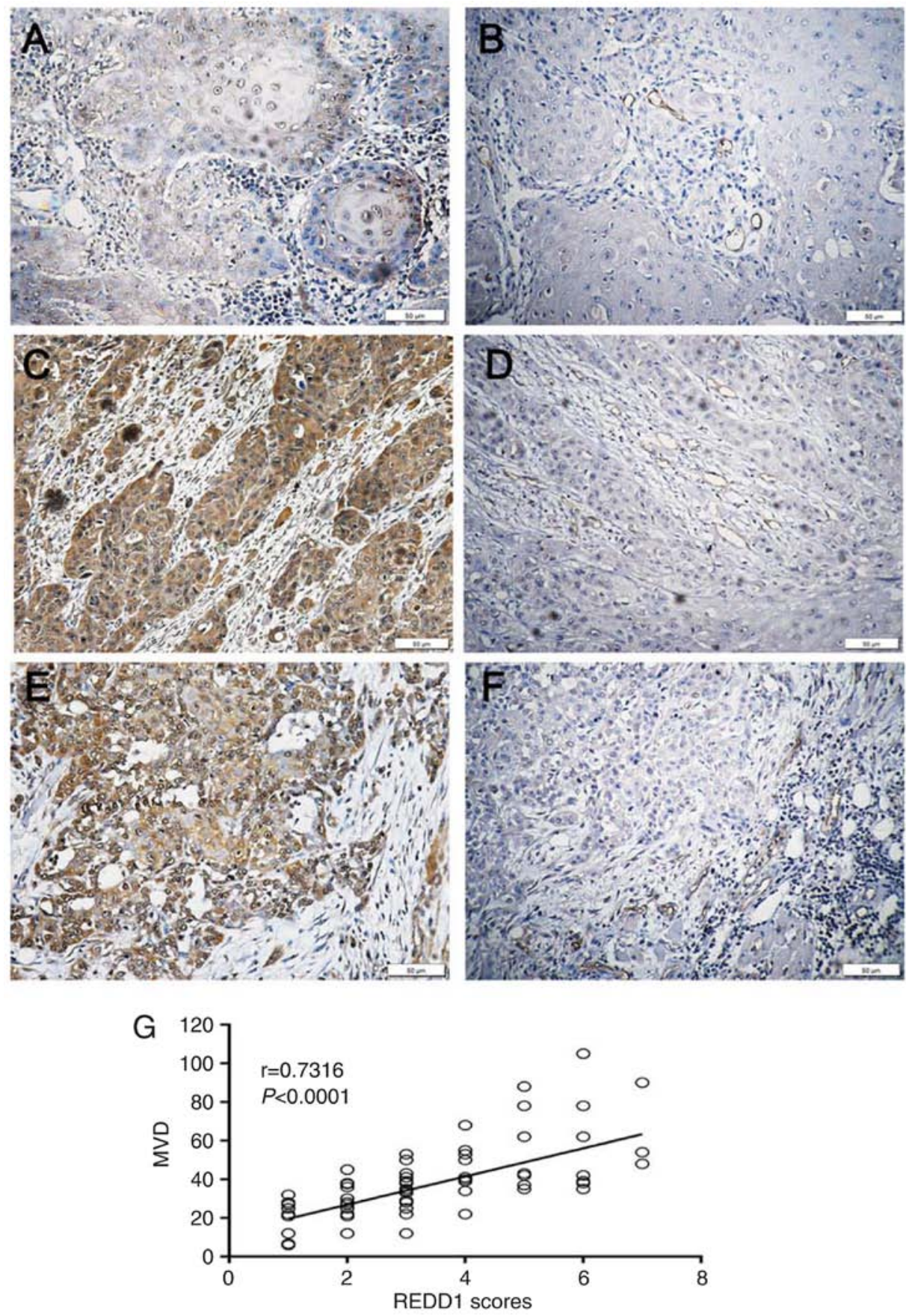

Figure 4. Representative image showing the positive association between REDD1 expression and MVD in OSCC tissues. CD34 was mainly expressed in vascular endothelial cells, which was assessed to determine MVD values. The median MVD count was 35. (A) REDD1 negative/weak expression in highly-differentiated tumors. (B) MVD $\leq 35$ in highly-differentiated tumors. (C) REDD1 moderate expression in moderately differentiated tumors. (D) MVD $>35$ in moderately differentiated tumors. (E) REDD1 strong-expression in poorly-differentiated tumors. (F) MVD $>35$ in poorly-differentiated tumors. Scale bar, $50 \mu \mathrm{m}$. (G) Results demonstrated that REDD1 expression and MVD were positively correlated ( $\mathrm{r}=0.7316$; P<0.001). MVD, microvessel density; OSCC, oral squamous cell carcinoma; REDD1, regulated in development and DNA damage responses 1. 

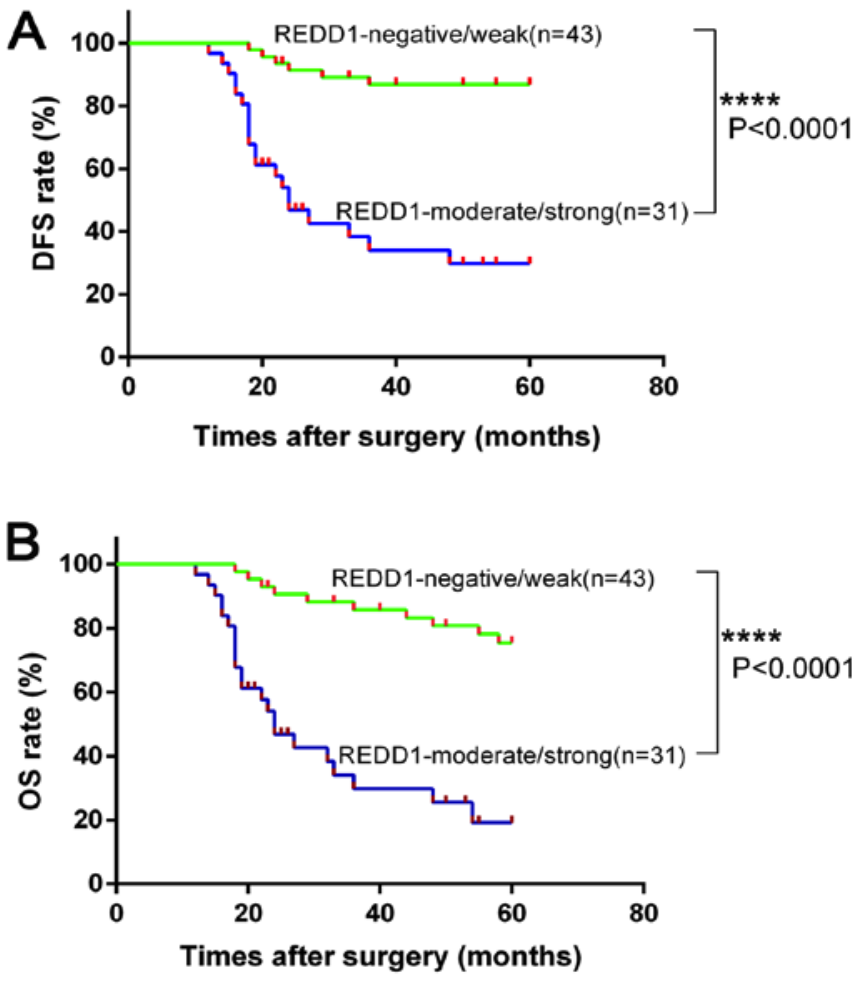

Figure 5. Kaplan-Meier analysis of DFS and OS in patients with oral squamous cell carcinoma. Patients with negative/weak expression of REDD1 had higher (A) DFS and (B) OS rates compared with patients with moderate/strong expression. ${ }^{* * * *} \mathrm{P}<0.0001$. DFS, disease free survival; OS, overall survival; REDD1, regulated in development and DNA damage responses 1.

bladder urothelial carcinoma (43). REDD1-mediated signaling abnormalities may also disrupt energy homeostasis and regulation of tumorigenesis through multiple pathways (31). Hypoxia-induced mTOR regulation has been reported to be essential for the regulation of HIF activity and the regulation of HIF-induced REDD1 (20). The HIF pathway is therefore considered a master regulator of angiogenesis (35). However, to the best of our knowledge, correlation between high REDD1 expression and angiogenesis has not yet been investigated in OSCC. REDD1 activation can inhibit mTORC1 via TSC1/2, which acts as a negative regulator of mTORC1 activity $(31,43)$. Simultaneously, REDD1 can also inhibit mTORC1 activity via the TSC1/2 complex in the H1299 lung cancer cell line (44). Similarly, the present study demonstrated that REDD1 expression was significantly higher in OSCC samples compared with normal tissue and that MVD was increased, indicating that HIF-inducible REDD1 may have a regulatory role in hypoxic signaling in OSCC. These findings suggested that mTORC1 inhibition may occur via the stable expression of REDD1, which may promote angiogenesis by modulating HIF transcription. Hypoxia and HIF activation have profound effects on tumor biology, and HIF-1 $\alpha$ and HIF- $2 \alpha$ are associated with numerous cancers, including cancers of the brain, breast, colon, head and neck, liver, lung, skin and pancreas $(5,45,46)$, for which poor prognosis is associated with metastasis. The present study highlighted the importance of REDD1 in the hypoxia-dependent regulation of MVD. Further investigation on the association between REDD1, mTOR and HIF-1 $\alpha$ is therefore required. The results form this study also indicated that, like hypoxia, REDD1 induction may stimulate angiogenesis.

Defective angiogenesis and decrease in blood supply cause increased tumor glycolysis $(22,47)$. Subsequently, cancer cells have a reduced oxidative metabolism and initiate ATP protection by limiting protein synthesis, which is an energy-consuming process $(47,48)$. These cells can therefore exhibit chemoresistance and radioresistance, affecting the chemoradiosensitivity of the entire tumor and further reducing the 5-year survival rate of patients with cancer $(49,50)$. Most patients with advanced OSCC need chemoradiotherapy following surgery; however, REDD1 overexpression may affect radiotherapy and chemotherapy efficacy. The findings from the present study suggested that patients with OSCC and high REDD1 expression may have a poor prognosis, be prone to recurrence, would exhibit reduced sensitivity to postoperative radiochemotherapy, as previously described $(43,51,52)$. This hypothesis will be further investigated in a future study. Although the present study revealed that REDD1 overexpression increases MVD in OSCC tissues, highly irregular, leaky and dysfunctional blood vessels might not increase sensitivity to chemotherapy and radiotherapy (35). The present study demonstrated that patients with OSCC and high REDD1 expression had poorer prognosis and shorter DFS and OS compared with patients with low REDD1 expression, suggesting that REDD1 expression may affect the 5-year survival of patients with OSCC. Thus, it can be concluded that the upregulation of this marker might predict poor survival in OSCC.

In conclusion, the present study demonstrated that the expression of the mTORC1 inhibitor REDD1 was positively correlated with tumor MVD. REDD1 may therefore be considered as a key regulatory checkpoint that could coordinate vascular growth signaling inputs. In addition, REDD1 overexpression may serve as a biomarker of adverse prognosis in OSCC progression. REDD1, which is a part of a network of signaling molecules comprising the mTOR pathway, may also represent a novel therapeutic target that could be used alone or in combination with other therapies targeting MVD, in order to stop the development and progression of OSCC.

\section{Acknowledgements}

The authors would like to thank Professor Qingjie Wang (Institute of Basic Medical Sciences, Qilu Hospital, Shandong University, Shandong, China) for his technical support during this study.

\section{Funding}

This study was supported by the National Nature Science Foundation of China (grant nos. 81702677, 81672606 and 81502340), the Natural Science Foundation of Shandong Province (grant nos. ZR2016HM39 and ZR2014HQ012) and the Youth Foundation of the Affiliated Hospital of Qingdao University (grant no. 201836).

\section{Availability of data and material}

The datasets used and analyzed during the current study are available from the corresponding author on reasonable request. 


\section{Authors' contributions}

YF, KS and NW performed the experiments and wrote the manuscript. WS, LC and BP participated in the design of the study and collected data. CW and NW performed the analysis of the patients' clinicopathological characteristics. All authors contributed to the writing of the manuscript and approved the final version.

\section{Ethics approval and consent to participate}

All patients provided their full consent to participate in the present study. This study was approved by the Institutional Medical Ethics Committee of the Affiliated Hospital of Qingdao University, and all procedures were performed in accordance with the 1964 Helsinki declaration and its later amendments or comparable ethical standards.

\section{Patient consent for publication}

Not applicable.

\section{Competing interests}

The authors declare that they have no competing interests.

\section{References}

1. Pouysségur J, Dayan F and Mazure NM: Hypoxia signalling in cancer and approaches to enforce tumour regression. Nature 441: 437-443, 2006

2. Gatenby RA and Gillies RJ: Why do cancers have high aerobic glycolysis? Nat Rev Cancer 4: 891-899, 2004.

3. Isa AY, Ward TH, West CM, Slevin NJ and Homer JJ: Hypoxia in head and neck cancer. Br J Radiol 79: 791-798, 2006.

4. Janssen HL, Haustermans KM, Balm AJ and Begg AC: Hypoxia in head and neck cancer: How much, how important? Head Neck 27: 622-638, 2005.

5. Göttgens EL, Ostheimer C, Span PN, Bussink J and Hammond EM: HPV, hypoxia and radiation response in head and neck cancer. Br J Radiol 14: 20180047, 2018.

6. Bredell MG, Ernst J, El-Kochairi I, Dahlem Y, Ikenberg K and Schumann DM: Current relevance of hypoxia in head and neck cancer. Oncotarget 7: 50781-50804, 2016.

7. Kishimoto K, Yoshida S, Ibaragi S, Yoshioka N, Okui T, Hu GF and Sasaki A: Hypoxia-induced up-regulation of angiogenin besides VEGF, is related to progression of oral cancer. Oral Oncol 48: 1120-1127, 2012

8. Brennan PA, Mackenzie N and Quintero M: Hypoxia-inducible factor 1alpha in oral cancer. J Oral Pathol Med 34: 385-389, 2005

9. Sano D and Myers JN: Metastasis of squamous cell carcinoma of the oral tongue. Cancer Metastasis Rev 26: 645-662, 2007.

10. Siegel RL, Miller KD and Jemal A: Cancer statistics, 2018. CA Cancer J Clin 68: 7-30, 2018.

11. Ghani WMN, Ramanathan A, Prime SS, Yang YH, Razak IA Abdul Rahman ZA, Abraham MT, Mustafa WMW, Tay KK, Kallarakkal TG, et al: Survival of oral cancer patients in different ethnicities. Cancer Invest 37: 275-287, 2019.

12. Muñoz-Guerra MF, Fernández-Contreras ME, Moreno AL, Martin ID, Herráez B and Gamallo C: Polymorphisms in the hypoxia inducible factor 1-alpha and the impact on the prognosis of early stages of oral cancer. Ann Surg Oncol 16: 2351-2358, 2009.

13. Liu L, Cash TP, Jones RG, Keith B, Thompson CB and Simon MC Hypoxia-induced energy stress regulates mRNA translation and cell growth. Mol Cell 21: 521-531, 2006.

14. Arsham AM, Howell JJ and Simon MC: A novel hypoxiainducible factor-independent hypoxic response regulating mammalian target of rapamycin and its targets. J Biol Chem 278: 29655-29660, 2003

15. Foster KG and Fingar DC: Mammalian target of rapamycin (mTOR): Conducting the cellular signaling symphony. J Biol Chem 285: 14071-14077, 2010.
16. Ma XM and Blenis J: Molecular mechanisms of mTOR-mediated translational control. Nat Rev Mol Cell Biol 10: 307-318, 2009.

17. Corradetti MN, Inoki K and Guan KL: The stress-inducted proteins RTP801 and RTP801L are negative regulators of the mammalian target of rapamycin pathway. J Biol Chem 280: 9769-9772, 2005.

18. Ellisen LW, Ramsayer KD, Johannessen CM, Yang A, Beppu H, Minda K, Oliner JD, McKeon F and Haber DA: REDD1, a developmentally regulated transcriptional target of p63 and p53, links p63 to regulation of reactive oxygen species. Mol Cell 10: 995-1005, 2002.

19. Sofer A, Lei K, Johannessen CM and Ellisen LW: Regulation of mTOR and cell growth in response to energy stress by REDD1. Mol Cell Biol 25: 5834-5845, 2005.

20. Brugarolas J, Lei K, Hurley RL, Manning BD, Reiling JH, Hafen E, Witters LA, Ellisen LW and Kaelin WG Jr: Regulation of mTOR function in response to hypoxia by REDD1 and the TSC1/TSC2 tumor suppressor complex. Genes Dev 18: 2893-2904, 2004.

21. Adel E, John C, Jennifert G, Takashi T and Pieter S: WHO classification of head and neck tumours. IARC Press, Lyon, pp105-131, 2017.

22. National Comprehensive Cancer Network (NCCN): NCCN clinical practice guidelines in oncology-Head and Neck cancers. NCCN Org:Version 2, 2018.

23. Wang N, Wang Q, Chi J, Xiang F, Lin M, Wang W, Wei F and Feng Y: Carcinoembryonic antigen cell adhesion molecule 1 inhibits the antitumor effect of neutrophils in tongue squamous cell carcinoma. Cancer Sci 110: 519-529, 2019.

24. Wang N, Wang QJ, Feng YY, Shang W and Cai M: Overexpression of chemerin was associated with tumor angiogenesis and poor clinical outcome in squamous cell carcinoma of the oral tongue. Clin Oral Investig 18: 997-1004, 2014.

25. Livak KJ and Schmittgen TD: Analysis of relative gene expression data using real-time quantitative PCR and the 2(-Delta Delta $\mathrm{C}(\mathrm{T}))$ method. Methods 25: 402-408, 2001.

26. Wang N, Feng Y, Wang Q, Liu S, Xiang L, Sun M, Zhang X, Liu G, Qu X and Wei F: Neutrophils infiltration in the tongue squamous cell carcinoma and its correlation with CEACAM1 expression on tumor cells. PLoS One 9: e89991, 2014.

27. Weidner N, Semple JP, Welch WR and Folkman J: Tumor angiogenesis and metastasis-correlation in invasive breast carcinoma N Engl J Med 324: 1-8, 1991.

28. Hu MY, Huang PL, Ma Y, Ling SK, Li Y, Chen BA and Xu YS: Effect of Redd1 loss on proliferation and metastasis of pancreatic cancer cells with KrasG12D-LOH by inhibiting glycolysis. J Clin Oncol (suppl) 35: 2017. DOI: 10.1200/JCO.2017.35.15_suppl. e1574

29. Dennis MD, McGhee NK, Jefferson LS and Kimball SR: Regulated in DNA damage and development 1 (REDD1) promotes cell survival during serum deprivation by sustaining repression of signaling through the mechanistic target of rapamycin in complex 1 (mTORC1). Cell Signal 25: 2709-2716, 2013.

30. Chang B, Liu GZ, Yang G, Mercado-Uribe I, Huang M and Liu J: REDD1 is required for RAS-mediated transformation of human ovarian epithelial cells. Cell Cycle 8: 780-786, 2009.

31. DeYoung MP, Horak P, Sofer A, Sgroi D and Ellisen LW: Hypoxia regulates TSC1/2-mTOR signaling and tumor suppression through REDD1-mediated 14-3-3 shuttling. Gene Dev 22: 239-251, 2008 .

32. Yun SM, Woo SH, Oh ST, Hong SE, Choe TB, Ye SK, Kim EK, Seong MK, Kim HA, Noh WC, et al: Melatonin enhances arsenic trioxide-induced cell death via sustained upregulation of Redd1 expression in breast cancer cells. Mol Cell Endocrinol 422: 64-73, 2016.

33. Chang B, Meng J, Zhu H, Du X, Sun L, Wang L, Li S and Yang G: Overexpression of the recently identified oncogene REDD1 correlates with tumor progression and is an independent unfavorable prognostic factor for ovarian carcinoma. Diagn Pathol 13: 87, 2018.

34. Jia W, Chang B, Sun L, Zhu H, Pang L, Tao L, Zou H, Du J, Dong Y, Qi Y, et al: REDD1 and p-AKT over-expression may predict poor prognosis in ovarian cancer. Int J Clin Exp Pathol 7: 5940-5949, 2014

35. Krock BL, Skuli N and Simon MC: Hypoxia-induced angiogenesis: Good and evil. Genes Cancer 2: 1117-1133, 2011.

36. Wang H, Kubica N, Ellisen LW, Jefferson LS and Kimball SR: Dexamethasone represses signaling through the mammalian target of rapamycin in muscle cells by enhancing expression of REDD1. J Biol Chem 281: 39128-39134, 2006. 
37. McGhee NK, Jefferson LS and Kimball SR: Elevated corticosterone associated with food deprivation upregulates expression in rat skeletal muscle of the mTORC1 repressor, REDD1. J Nutr 139: 828-834, 2009

38. Li XH, Ha CT, Fu D and Xiao M: REDD1 protects osteoblast cells from gamma radiation-induced premature senescence. PLoS One 7: e36604, 2012.

39. Shoshani T, Faerman A, Mett I, Zelin E, Tenne T, Gorodin S, Moshel Y, Elbaz S, Budanov A, Chajut A, et al: Identification of a novel hypoxia-inducible factor 1-responsive gene, RTP801, involved in apoptosis. Mol Cell Biol 22: 2283-2293, 2002.

40. Whitney ML, Jefferson LS and Kimball SR: ATF4 is necessary and sufficient for ER stress-induced upregulation of REDD1 expression. Biochem Biophys Res Commun 379: 451-455, 2009.

41. Lee M, Bikram M, Oh S, Bull DA and Kim SW: Sp1-dependent regulation of the RTP801 promoter and its application to hypoxia-inducible VEGF plasmid for ischemic disease. Pharm Res 21: 736-741, 2004.

42. Shen X, Chang LG, Hu MY, Yan D, Zhou LN, Ma Y, Ling SK, Fu YQ, Zhang SY, Kong B and Huang PL: KrasG12D-LOH promotes malignant biological behavior and energy metabolism of pancreatic ductal adenocarcinoma cells through the mTOR signaling pathway. Neoplasma 65: 81-88, 2018.

43. Zeng Q, Liu J, Cao P, Li J, Liu X, Fan X, Liu L, Cheng Y, Xiong W, Li J, et al: Inhibition of REDD1 sensitizes bladder urothelial carcinoma to paclitaxel by inhibiting autophagy. Clin Cancer Res 24: 445-459, 2018.

44. Jin HO, Hong SE, Kim JH, Choi HN, Kim K, An S, Choe TB, Hwang CS, Lee JH, Kim JI, et al: Sustained overexpression of Reddl leads to Akt activation involved in cell survival. Cancer Lett 336: 319-324, 2013

45. Gong J, Zhou S and Yang S: Vanillic acid suppresses HIF-1 $\alpha$ expression via inhibition of mTOR/p70S6K/4E-BP1 and Raf/MEK/ERK pathways in human colon cancer HCT116 cells. Int J Mol Sci 20: pii: E465, 2019.

46. Tong WW, Tong GH and Liu Y: Cancer stem cells and hypoxia-inducible factors (Review). Int J Oncol 53: 469-476, 2018.
47. Ostergaard L, Tietze A, Nielsen T, Drasbek KR, Mouridsen K, Jespersen SN and Horsman MR: The relationship between tumor blood flow, angiogenesis, tumor hypoxia and aerobic glycolysis. Cancer Res 73: 5618-5624, 2013.

48. Ma T, Patel H, Babapoor-Farrokhran S, Franklin R, Semenza GL, Sodhi A and Montaner S: KSHV induces aerobic glycolysis and angiogenesis through HIF-1-dependent upregulation of pyruvate kinase 2 in Kaposi's sarcoma. Angiogenesis 18: 477-488, 2015

49. Steinbichler TB, Alshaimaa A, Maria MV, Daniel D, Herbert R, Jozsef D and Ira-Ida S: Epithelial-mesenchymal crosstalk induces radioresistance in HNSCC cells. Oncotarget 9: 3641-3652, 2017.

50. Chan N, Koritzinsky M, Zhao H, Bindra R, Glazer PM, Powell S, Belmaaza A, Wouters B and Bristow RG: Chronic hypoxia decreases synthesis of homologous recombination proteins to offset chemoresistance and radioresistance. Cancer Res 68: 605-614, 2008.

51. Clavo B, Robaina F, Fiuza D, Ruiz A, Lloret M, Rey-Baltar D, Llontop P, Riveros A, Rivero J, Castañeda F, et al: Predictive value of hypoxia in advanced head and neck cancer after treatment with hyperfractionated radio-chemotherapy and hypoxia modification. Clin Transl Oncol 19: 419-424, 2017.

52. Carden CP, Stewart A, Thavasu P, Kipps E, Pope L, Crespo M, Miranda S, Attard G, Garrett MD, Clarke PA, et al: The association of PI3 kinase signaling and chemoresistance in advanced ovarian cancer. Mol Cancer Ther 11: 1609-1617, 2012.

This work is licensed under a Creative Commons Attribution-NonCommercial-NoDerivatives 4.0 International (CC BY-NC-ND 4.0) License. 